\section{Jornalismo efêmero: o uso de stories do Instagram pela Folha de S.Paulo}

\author{
Raquel Ritter Longhi \\ Lia Gabriela Pagoto
}

\section{Resumo:}

As transformações oriundas da nova morfologia social, mediada pela tecnologia, trouxeram alterações significativas no modo de consumir e produzir notícias. $\mathrm{Na}$ esteira da mobilidade, sites de redes sociais, como o Instagram, por meio dos Stories, trazem nova luz para as ideias de efemeridade e instantaneidade jornalísticas. Depois de refletir sobre a emergência do efêmero na produção ciberjornalística, este artigo faz uma análise da adaptação de conteúdos jornalísticos para o Instagram Story através do \#nãodurmasemsaber, veiculado diariamente no perfil da Folha de S.Paulo no Instagram. Por meio de análise de conteúdo e observação simples, o artigo verifica de que forma o veículo se adapta à ferramenta nativa da rede social, verificando características da produção deste microformato jornalístico considerando os seguintes aspectos: volume e frequência; recursos e formas expressivas utilizadas. A conclusão mostra que, no caso em tela, ainda é tímida a exploração dos recursos entregues pelo microformato, embora este obedeça, em certa medida, à nova lógica de consumo informacional, que, por sua vez, responde a uma dialética temporal do presente. Desta forma, pode-se afirmar que o formato se insere na racionalidade contemporânea que reflete a efemeridade.

Palavras-chave: Instagram. Notícia efêmera. Stories.

\section{Ephemeral journalism: the use of Instagram Stories by Folha de S.Paulo}

\section{Abstract:}

The transformations arising from the new social morphology, mediated by technology, have brought significant changes in the ways of consuming and producing news. In the wake of mobility, social networks such as Instagram, with the Stories function, bring new light to the ideas of ephemerality and journalistic instantaneity. After reflecting on the emergence of the ephemeral in cyberjournalistic production, this article analyses the adaptation of journalistic content for Instagram Story through \#nãodurmasemsaber, broadcasted daily by Folha de S.Paulo's Instagram profile. Using both content analysis and simple observation, this article verifies how the news vehicle adapts to the native tool of the social network, checking characteristics of the production of this journalistic microformat considering the following aspects: volume and frequency; resources and expressive forms used. The conclusion shows that, in the case at hand, the exploration of the resources delivered by the microformat is still timid, although this microformat obeys, to a certain extent, the new logic of informational consumption, which also responds to a temporal dialectics of the present. In this way, it can be said that the format is part of the contemporary rationality that reflects ephemerality.

Keywords: Instagram. Ephemerality. Stories.
Recebido em: 06.07.20

Aprovado em: 17.03.21

\section{Raquel Ritter Longhi \\ Professora no programa de Pós-Graduação em Jornalismo e do Curso de Jornalismo da Univer- sidade Federal de Santa Catarina - UFSC. \\ E-mail: raqlonghi@ gmail.com}

\section{Lia Gabriela Pagoto}

Doutoranda no Programa de Pós-Graduação em Jornalismo da Universidade Federal de Santa Catarina (UFSC).

E-mail: liagabrielapagoto@gmail.com 


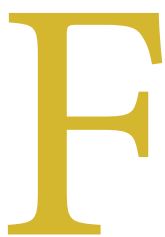

ormatos breves de informação apareceram num primeiro momento a partir da plataforma de mídia social Twitter, em 2010, passando pelo Snapchat e mais recentemente explodindo com o Story, no que parece ser uma tendência importante para o jornalismo no desafio de conquistar mais audiência utilizando as redes sociais. Microformatos como os stories o que trazem, na verdade, são lentes para perceber a emergência do efêmero na atividade jornalística. Seu uso crescente pelo jornalismo mostra uma tentativa de adequar-se às novas configurações do ecossistema midiático e adaptar-se à velocidade e à fugacidade da informação. Um desafio para a atividade jornalística. De fato, notícias efêmeras têm dominado de forma crescente a atenção e o consumo jornalísticos: são produzidas e distribuídas em "pílulas" visuais que utilizam recursos expressivos originais da mídia social. Neste artigo, revisitamos o conceito de efemeridade da notícia para compreender as transformações em curso, como a velocidade, a instantaneidade e a fugacidade que plataformas como o Instagram conferiram à informação.

O Instagram já atingiu a marca de 1 bilhão de usuários ativos ${ }^{1}$, um espaço gigantesco de distribuição para o jornalismo, portanto, e ainda, uma ferramenta para produção de conteúdos, com recursos oferecidos dentro do próprio aplicativo. Isso é apenas parte de mudanças acentuadas nas formas de produção e distribuição da notícia, sem falar do consumo. Tudo em modo turbo, subvertendo a lógica temporal à qual o jornalismo era submetido. Imbricada nesse ritmo cada vez mais vertiginoso de experimentar o tempo, da conexão ininterrupta, a efemeridade nas redes sociais torna-se intencional. As reflexões sobre a reconfiguração do tempo na atualidade jornalística e a compreensão de que o ritmo do jornalismo também responde ao sujeito moderno (Groth, 2011), apontam para a proeminência do jornalismo para stories, impulsionado pela ascensão das redes sociais, onde a efemeridade atinge seu ápice.

O interesse específico da análise proposta neste artigo é a adaptação de conteúdos jornalísticos para o Instagram Story, no caso em tela, o \#nãodurmasemsaber, veiculado diariamente no perfil da Folha de S.Paulo no aplicativo de mídia social. Depois de refletir sobre a efemeridade da notícia, e através de análise de conteúdo, o artigo verifica de que forma o veículo se adapta a este formato nativo da rede social, analisando as características de produção, considerando os seguintes aspectos: volume e frequência; recursos, e formas expressivas utilizadas. O corpus selecionado é composto por um conjunto de stories publicados pelo perfil no Instagram da Folha de S.Paulo. Para compor a amostra, selecionamos duas semanas (de 14 a 22 de janeiro de 2020) de stories do \#nãodurmasemsaber, veiculados diariamente. A metodologia utilizada foi a análise de conteúdo, por entendermos que ela permite a descrição sistemática, objetiva e quantitativa, além de possibilitar o agrupamento de características. Entre os objetivos específicos, pretendemos responder às perguntas: a) Como se dá a produção, em termos de volume e frequência? b) Quais são os recursos utilizados?

\section{O estado líquido da notícia: conteúdos efêmeros}

O conteúdo efêmero continuará crescendo. Esta é a primeira tendência para as redes sociais em 2020, apontada pelo relatório "Tendências das mídias sociais para 2020 e para os próximos anos", publicado pelo Influencers Marketing Hub, em dezembro de 2019. O estudo destaca que formatos como os stories tornaram-se cada vez mais populares porque os períodos de atenção das pessoas são curtos, e

${ }^{1}$ De acordo com o site Statista.com, acessado em maio de 2021. assim também o modo como elas consomem. Assim, eles são breves, atrativos e viciantes - as pessoas podem passar horas e horas deslocando-se de uma história a outra, segundo o mesmo estudo. 
A lógica de funcionamento da mídia digital contemporânea incorporou uma nova dimensão ao conceito de "efemeridade" para o jornalismo, especialmente a partir do surgimento de sites de redes sociais com as características do Snapchat e do Instagram Story.

O efêmero não é apenas a criação de conteúdos que podem ser consumidos em segundos ou minutos (GRAINGE, 2011), mas também trata de conteúdos que só podem ser visualizados em um determinado número de vezes ou por um período específico (ANDERSON, 2015).

O pensamento sobre a efemeridade aplicada à prática jornalística, porém, não é novidade: o pioneiro nos estudos de Jornalismo, Otto Groth (2011), já tratava o tema como inerente à atividade muito antes do surgimento dos sites de redes sociais, colocando-a como consequência de sua relação com a temporalidade e a sua afinidade com a periodicidade e a atualidade. Atualidade é uma das quatro características do jornal, para Groth, junto com periodicidade, universalidade e publicidade. Para o autor alemão, trata-se de um conceito de tempo: a atualidade é intrínseca ao presente imediato.

A razão da atualidade está na necessidade da vida das pessoas, na natureza teleológica da sua psique e na necessidade constante de informações o mais rápido possível sobre os respectivos mundos diante de si, o que também levou à invenção do jornal. (GROTH, 2011, p. 236).

As condições pelas quais um conteúdo é atual serão determinadas pela sua dependência com a universalidade, na relação do presente, com o passado e o futuro. Como sublinhamos em Groth (2011), "o presente enquanto atualidade se estende por um certo espaço temporal que a consciência percebe como continuidade", ou seja, o que é atual reduziu-se ao tempo a que aquilo diz respeito. O teórico português António Fidalgo revisita Groth para pensar o princípio da atualidade jornalística à luz dos novos tempos. Ele aponta para o fato de que, com a aceleração da vida cotidiana, há uma contração da atualidade:

Mas se é a consciência da actualidade que marca os limites desta, então compreende-se que com a aceleração da vida quotidiana tenha havido uma contracção da actualidade. Dantes o presente durava mais tempo que nos nossos dias. O que é actual reduziu-se drasticamente no que à extensão do tempo diz respeito. Há uns séculos atrás o presente durava mais e as notícias também viviam mais. Agora percebemos uma corrida contra o tempo em busca da actualidade, não só porque tal o exige o espírito capitalista que também anima as empresas noticiosas, mas porque a actualidade tende a contrair-se cada vez mais. (FIDALGO, 2004, p. 8).

Esse processo que se inscreve na aceleração do tempo e flexibilização do espaço não atinge somente a produção mas, especialmente, as práticas de consumo. Harvey (2004) descreveu a contração citada por Fidalgo (2004) com o conceito de compressão espaciotemporal. Para ele, a compressão está relacionada à "aceleração do ritmo da vida, ao mesmo tempo que venceu as barreiras espaciais em tal grau que, por vezes, o mundo parece encolher sobre nós" (HARVEY, 2004, p. 219). O que vemos nas últimas décadas é uma "intensa fase de compressão do tempo-espaço que tem tido um impacto desorientador e destrutivo sobre as práticas político-econômicas, sobre o equilíbrio do poder de classe, bem como sobre a vida social e cultural" (HARVEY, 2004, p. 257). A partir do prisma da temporalidade, essa onda aceleratória nos permite pensar mais profundamente na efemeridade da notícia no âmbito de redes sociais, onde vigora o reinado do presente.

Assim, percebe-se que, além da essência da notícia, o canal e a forma de consumo também são caracterizados pela efemeridade intencional. Os aplicativos de redes sociais, mais do que o compromisso com a memória, reforçam a fluidez. 
Vasconcelos (2017) também considera que a efemeridade é uma condição do jornalismo e observa que nesses aplicativos ela ganha contornos extremos. À mesma conclusão chegam Wanderley et al. (2016):

(...) muda a forma de consumir conteúdo, e por sua vez, vale-se do conceito de "liquidez" de forma nítida, através do seu principal serviço, o compartilhamento de fotos acompanhadas por mensagens, com tempo pré-programado para autodestruição e a rápida substituição do fato em si por outro de maior ou menor importância, apenas pela necessidade de "efemerizar” e tornar líquido aquele comportamento. (WANDERLEY ET AL., 2016, p. 10).

Se em outros tempos a atualidade de uma notícia era de um dia inteiro, ou seja, a notícia se tornava antiga somente com a próxima publicação, na atualidade móvel e circulante esse processo saltou para segundos com o uso dos stories. $\mathrm{Na}$ órbita do conceito de aceleração social, a notícia perde sua atualidade cada vez mais rapidamente.

Uma sociedade na qual a mensagem relevante é apenas o que é novo e que, depois de um tempo pré-determinado perde seu valor, é denominada por Bauman de sociedade líquida.

Líquidos mudam de forma muito rapidamente, sob a menor pressão. Na verdade, são incapazes de manter a mesma forma por muito tempo. No atual estágio "líquido" da modernidade, os líquidos são deliberadamente impedidos de se solidificarem. (BAUMAN, 2010).

"Fluidez", diz o autor - sublinhando a opção da Enciclopédia Britânica em oferecer uma metáfora para a era moderna -, embasa esta ideia:

O que todas essas características dos fluidos mostram, em linguagem simples, é que os líquidos, diferentemente dos sólidos, não mantêm sua forma com facilidade. Os fluidos, por assim dizer, não fixam o espaço nem prendem o tempo. Enquanto os sólidos têm dimensões espaciais claras, mas neutralizam o impacto e, portanto, diminuem a significação do tempo (resistem efetivamente a seu fluxo ou o tornam irrelevante), os fluidos não se atêm muito a qualquer forma e estão constantemente prontos (e propensos) a mudá-la; assim, para eles, o que conta é o tempo, mais do que o espaço que lhes toca ocupar; espaço que, afinal, preenchem apenas "por um momento". Em certo sentido, os sólidos suprimem o tempo; para os líquidos, ao contrário, o tempo é o que importa. (BAUMAN, 2001, p. 08)

A busca incessante por conexões efêmeras e fluídas e a grande volatilidade dos conteúdos, autodestrutivos e que logo se tornam obsoletos, são também características da sociedade líquida. Talvez seja por isso que esses aplicativos detenham tanto espaço na vida cotidiana. Por ter a efemeridade enquanto característica fundante e por ser um produto do seu tempo, o jornalismo, ao apropriar-se de plataformas voláteis de compartilhamento de conteúdo, como os stories do Instagram, mostra que esse movimento é quase natural. Mesmo assim, não menos desafiante.

\section{O efêmero e o fator Redes Sociais para o jornalismo}

${ }^{2}$ Conforme o site Statista, o número de usuários diários únicos (Daily Active Users) do Instagram evoluiu de 100 milhões em outubro de 2016 para 500 milhões em janeiro de 2019, o que explica esse crescimento.

O Instagram vem sendo crescentemente utilizado pelo jornalismo como espaço de distribuição de conteúdo, e o formato story parece estar no topo dos mais utilizados, tanto pelos usuários regulares como pelos veículos ${ }^{2}$. Há algum tempo que pesquisas mostram o avanço do uso das redes sociais pelo jornalismo, especialmente na qualidade de portas de entrada (NEWMAN, 2009), para a notícia. Vázquez-Herrero et al. (2019), ao considerar tal movimento, reforçam que, ao expor mais usuários a conteúdo noticioso de modo acidental, como observam Ahmadi and Wohn (2019, p.7), citados pelos autores, as organizações de mídia podem atrair mais consumidores de notícias e obter maior vantagem competitiva. Da mesma forma, esse tipo de consumo de notícias não intencional tende 
a ser passageiro e efêmero (...) pois os usuários passam menos tempo assistindo essas histórias e sua atenção é breve, parcial e fragmentada (BOCZKOWSKI et al., 2017). Assim, "a efemeridade é agora um componente central da experiência do usuário para muitas plataformas sociais" (BAYER et al., 2016, p. 957). O público que consome esse tipo de conteúdo pode ser definido como "um público ad hoc efêmero e engajado, formado em torno de uma causa facilitada pelas mídias sociais (HERMIDA, 2016, p. 90)”. (VÁZQUEZ-HERRERO et al, 2019, p. 2). ${ }^{3}$

Se as transformações oriundas da nova morfologia social implicaram no modo consumir notícia, também impactaram as rotinas de produção, edição e apuração das notícias. O aumento expressivo do uso dessas plataformas também aponta para o futuro do ecossistema midiático.

Como os usuários dos dispositivos móveis estão procurando notícias cada vez mais atualizadas, a mídia deve produzir formatos nativos ajustados a esses padrões, caracterizados pelo acesso mais rápido e de maior pontualidade. (WOLF \& SCHNAUBER, 2015 apud VÁZQUEZ-HERRERO et al, 2019, p. 2).

Quando foi criado, em 2011, o Snapchat popularizou um alto grau de efemeridade. Nesse estágio do aplicativo, só era possível trocar mensagens de fotos entre usuários, e as mensagens se autodestruíam assim que abertas, desaparecendo tanto do celular de quem recebia o conteúdo quanto dos servidores do aplicativo. Para integralizar uma lógica temporal ao aplicativo, culturalmente comum, o Snapchat passou a incluir a possibilidade de o usuário criar uma narrativa do seu dia-a-dia através da funcionalidade Story. Os conteúdos, fotos ou vídeos, podem ser adicionados à Story a qualquer momento, cada um podendo ser visualizado por até 24 horas após a publicação. A possibilidade de criar narrativas ampliou o interesse no aplicativo, que logo se popularizou com o uso por diversas celebridades e em seguida passando a chamar a atenção dos veículos de comunicação. Com a utilização do aplicativo pelo jornalismo, notícias sobre o crescimento e as novidades da plataforma colocaram em evidência a efemeridade do conteúdo produzido para o Story. Bradshaw (2016, p. 1), que reuniu informações sobre o aplicativo e dicas de como utilizá-lo para o fazer jornalístico, iniciou seu livro dizendo que, dentre as muitas tecnologias que os jornalistas tiveram de lutar para incorporar na produção de conteúdo, o Snapchat talvez seja a mais frustrante de todas.

Por que estamos tão desconfortáveis com o Snapchat? (...) Bem, em primeiro lugar, há a natureza efêmera da ferramenta: criar conteúdo projetado para desaparecer é precisamente o oposto do que os jornalistas aspiram. (BRADSHAW, 2016, p. 1)

O Story no Instagram segue a mesma lógica. Lançada em agosto de 2016, essa funcionalidade atua de forma idêntica às stories do Snapchat: vinculado à mesma conta do Instagram, o usuário publica fotos e vídeos de até 15 segundos que ficam disponíveis a seus seguidores durante 24 horas. Tamanha foi a relevância da adição que, segundo o Global social media ranking 2017 (STATISTA, 2017), em apenas dez meses, as stories do Instagram haviam alcançado 250 milhões de usuários ativos diários, o que representava cerca de um terço de toda a base de usuários mensais do aplicativo de mídia social e bem acima do total de $166 \mathrm{mi}$ lhões de todo o aplicativo Snapchat à época.

\section{\#nãodurmasemsaber: Um resumo diário da Folha de S.Paulo}

O Brasil está entre os três países com as maiores audiências do Instagram, ao lado dos Estados Unidos e da Índia - num contexto em que mais de dois terços do público global utiliza tal rede social. Somente no Instagram Story, o
${ }^{3}$ Tradução nossa. No original: (...) "ephemerality is now a central component of the user experience for many social platforms" (BAYER et al., 2016, p. 957). Audiences who consume these kinds of con- tents can be defined as "an engaged and ephemeral ad hoc public that has formed around a cause facilitated by social media (HERMIDA, 2016, p. 90)". 
número de usuários mensais ativos chega a 500 milhões. Um cenário gigantesco, portanto, de possibilidades de difusão de conteúdos para o jornalismo.

A análise de conteúdo do quadro \#nãodurmasemsaber, compartilhado diariamente nos stories do Instagram da Folha de S.Paulo foi feita sobre uma amostra colhida nos dias 14, 15, 16, 17 e 20, 21 e 22 de janeiro de 2020. Por ser uma plataforma de conteúdo efêmero, como já discutido, as postagens somem após um período de 24 horas. Dessa forma, foi utilizado, para captura dos arquivos, o software XRecorder, versão 1.2.1.3 para Android.

A Folha está no Instagram desde 2011 com o perfil @folhadespaulo 4 . Segundo Camilo (2020), o uso do Story pelo perfil da Folha se dá concomitante com o surgimento da ferramenta: "Começamos a usar o story assim que estreou, em agosto de 2016. Ali já vimos uma maneira de informar de uma maneira diferente". "Informar de uma maneira diferente", como colocado pelo editor de Instagram da Folha à época, foi também um modo de responder a uma demanda. Como apontou VanDik (2013), um meio de comunicação evolui com as táticas dos seus utilizadores cotidianos, nessa lógica, atender às expectativas do público que está cada vez mais imerso nos ambientes de efemeridades é também uma coevolução do jornalismo contemporâneo. Como afirmam Vázquez-Herrero et al. "histórias efêmeras se encaixam melhor em um visual e modelo de consumo ágil, pois sua navegação favorece a velocidade, contexto da conversa em rede". (VÁZQUEZ-HERRERO et al, 2019, p. 10).

Com o uso dos stories, a Folha aposta em informações rápidas, dinâmicas e com um design que chama atenção em meio ao fluxo contínuo de conteúdo ao qual os usuários estão expostos nos sites de redes sociais. Dentre os recursos oferecidos, estão vídeos, fotos, aplicação de filtros, emojis, gifs, hashtags, mensagens de texto com diversas fontes, edição, e ainda, seu compartilhamento em outras redes sociais digitais, assim como a interação entre os usuários por mensagens particulares, adição de hiperlinks e a marcação de outros usuários.

Acompanhando a evolução da plataforma, em 2018 a Folha decidiu levar aos leitores um resumo das notícias do dia, o \#nãodurmasemsaber. O perfil escolhe até oito notícias, sempre abrindo com política ou economia, mas com espaço para todas as editorias. Apresenta um formato nativo e padronizado, com abertura, apresentação de conteúdo e encerramento. $\mathrm{Na}$ abertura, é apresentado o nome do quadro, sempre com um fundo colorido e um GIF do próprio Instagram. Seguem as notícias do dia e a tela de encerramento - "créditos" da equipe responsável pelas reportagens e pela produção.

Para análise do corpus, os stories da @folhadespaulo foram separados em Grupo de Story (GS) e Unidade de Story (US). Um GS equivale a um episódio inteiro do \#nãodurmasemsaber. Já uma US equivale a uma unidade de story, que, por sua vez, compõe a narrativa de uma notícia do episódio.

${ }^{4}$ Atualmente contando com 2.2 milhões de seguidores, número atualizado diariamente pelo núcleo de produção de Instagram da Folha.
Figura 1 - telas de abertura

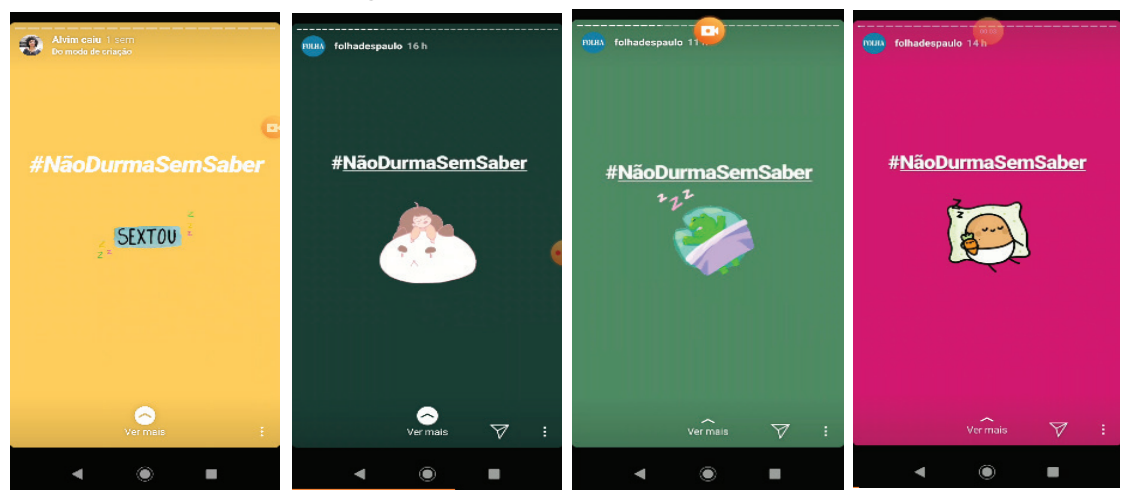

Fonte: Captura de tela. Elaborado pelas autoras. 
Figura 2 - telas de encerramento
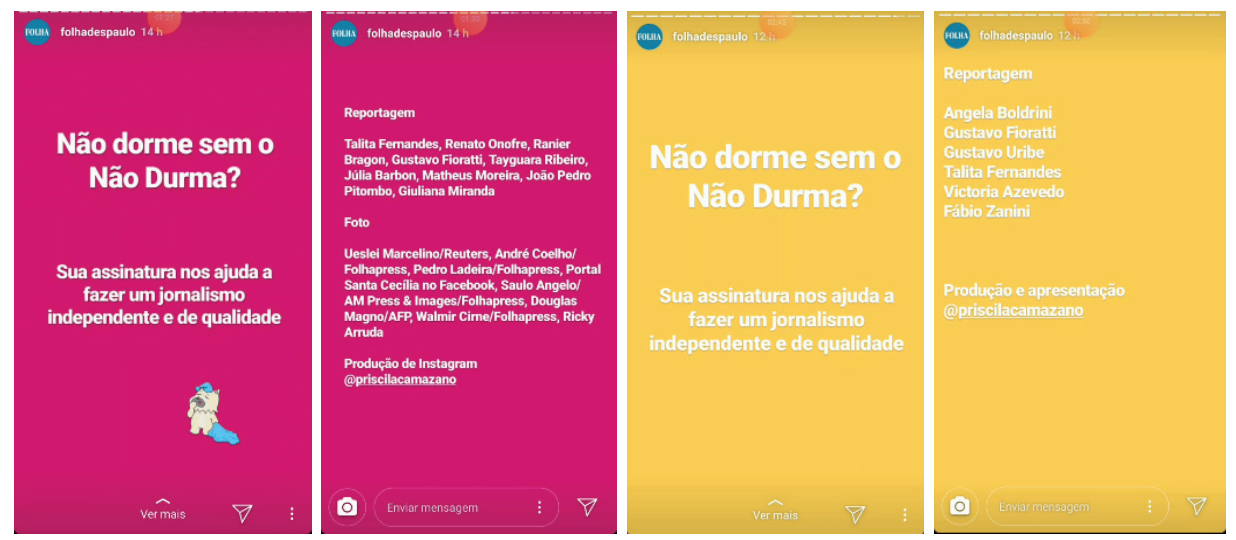

Fonte: Captura de tela. Elaborado pelas autoras.

As cores do quadro e a assinatura não são padronizadas, mas, no geral, há uma estética característica que responde aos conteúdos nativos da plataforma, por exemplo: a fonte utilizada para as notícias é a "clássico", ora com fundo, ora sem. As cores de cada US também respeitam a paleta de cores da foto da notícia (já pronta). Para o texto é feita a seleção de cor com o pincel do Instagram, respeitando assim a paleta de cores da imagem selecionada e mantendo um padrão mínimo de direção de arte.

Figura 3 - telas de notícias
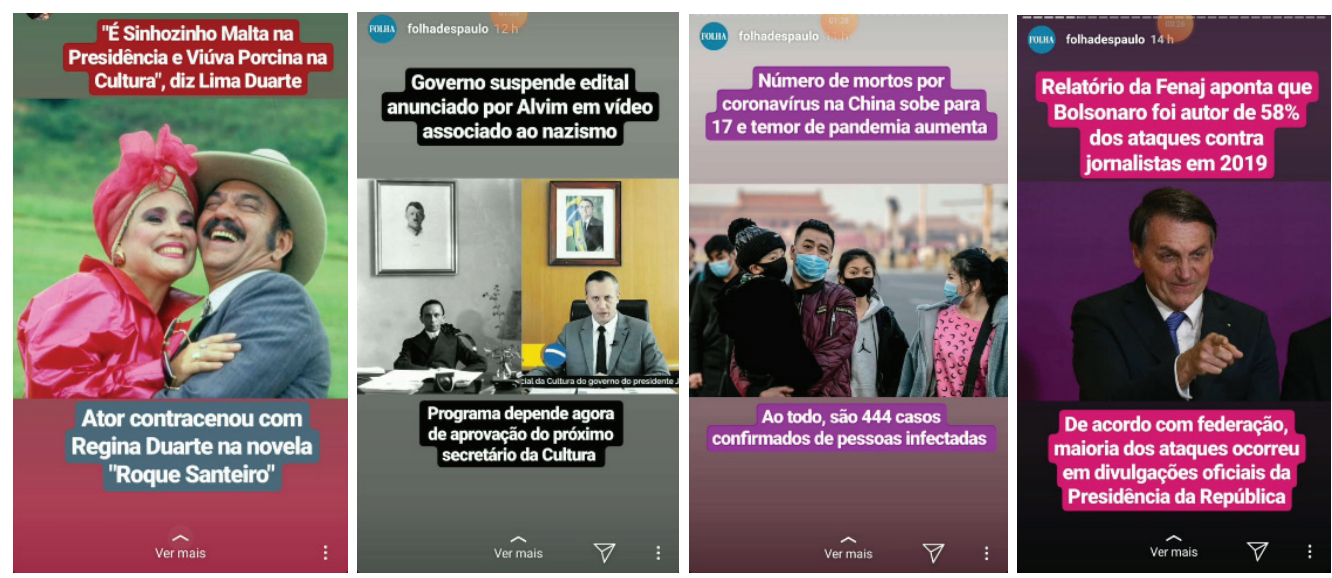

Fonte: Captura de tela. Elaborado pelas autoras.

Em relação ao formato, ainda que esse microformato tenha sido criado para utilização mobile, logo, vertical, a orientação padrão do conteúdo apresentado pelo \#nãodurmasemsaber é horizontal. Em toda amostra, somente o episódio de vídeo e uma US apresentaram a gramática vertical, nativa da plataforma. As demais US são apresentadas com uma foto horizontal centralizada e as informações relativas à notícia na parte superior e inferior da imagem.

A utilização das fotos em formato horizontal parece assinalar um diálogo de transição entre o tradicional e o novo, no jornalismo de microformatos. $\mathrm{O}$ impulsionamento do formato vertical, trazido por plataformas como o Snapchat e Instagram, especialmente com a ferramenta de Story e com a implementação do IGTV, em 2016, é reflexo da navegabilidade vertical imposta pelos smartphones. Newman (2016) aponta que nos Estados Unidos o tempo de visualização dos vídeos verticais já corresponde a $29 \%$ do total, o que em 2010 era de apenas 5\%. Ainda segundo o autor, os utilizadores do smartphone seguram os seus dispositivos na vertical durante $94 \%$ do tempo.

Se a transição das imagens das telas do cinema para dentro das casas por meio do aparelho de tevê foi uma transformação na forma de consumir as imagens visuais (SANTAELLA, 2013), é ainda maior quando essas cabem dentro do bolso e 
utilizam todo o ecrã disponível, agora vertical. Por isso é que refletir sobre a tendência de consumo e, principalmente, de produção de imagens verticais no jornalismo é importante, no âmbito das plataformas mobile. O caso da Folha parece assinalar um momento de transposição, assim como aconteceu no início do jornalismo online. A utilização das imagens produzidas para as notícias que são publicadas no site do jornal em formato de Story resulta na criação de um conteúdo híbrido - parte confeccionado na própria plataforma, caso dos recursos de texto e outros elementos visuais disponibilizados, e parte oriunda da produção tradicional do jornalismo, como imagens no modo paisagem, que favorecem ângulos amplos.

Em relação à quantidade, a média final da amostra ficou em sete notícias por edição do \#nãodurmasemsaber. Das 47 notícias veiculadas, 45 foram apresentadas em formato de texto + fotografia + hiperlink e duas em vídeo + texto + hiperlink. Cada notícia integrante de uma edição é composta, no mínimo, por duas US, exceção feita ao único episódio em formato vídeo, no qual foram apresentadas apenas duas notícias, logo, cada uma delas um grande número de Unidade de Story (US). Alguns assuntos, que possivelmente foram destaque no dia, têm mais US, chegando a seis. Somando abertura e o encerramento do quadro, um episódio comum do \#nãodurmasemsaber tem, em média, 22 US.

Um story pode durar, segundo o próprio Instagram, até 15 segundos. Se considerarmos que todos as US do \#nãodurmasemsaber duraram 15 segundos, um episódio regular não passaria de 3min30s. No entanto, os episódios da Folha são mais enxutos. Nossa amostra demonstrou que mesmo o episódio em vídeo não passou de 2 min52s. Em relação à frequência e periodicidade, o \#nãodurmasemsaber é veiculado todos os dias da semana, de segunda a sexta-feira - cinco edições por semana, sendo um por dia. Ainda que não faça parte deste recorte, é preciso pontuar que no final de semana que intercalou a amostra, compreendido entre os dias 18 e 19 de janeiro, a Folha publicou o que chamou de "\#nãodurmasemsaber - versão de pocket final de semana”. Neste episódio foram veiculadas três notícias e um total de 17 US.

No material coletado predominou o formato de narrativa visual. Do ponto de vista dos elementos expressivos, a narrativa é marcada, majoritariamente, pela composição de fotografia, texto e link de redirecionamento para o site da Folha. Em 53\% dos casos, o primeiro texto utilizado na notícia do Story, ou seja, que introduz o leitor na notícia de microformato, é o mesmo título da notícia que está no site da Folha. Nos demais casos, 47\%, o título é diferente, normalmente mais enxuto que o empregado no site. As informações que compõem o restante da narrativa, a sequência (as US) são as informações principais da matéria - o lead. Em alguns casos, é possível notar que a dinâmica de movimento de adição de conteúdo do story é utilizada para esclarecer, rapidamente, o leitor sobre um tema, como é possível ver na sequência de US abaixo:

Figura 4 - dinâmica de movimento de US

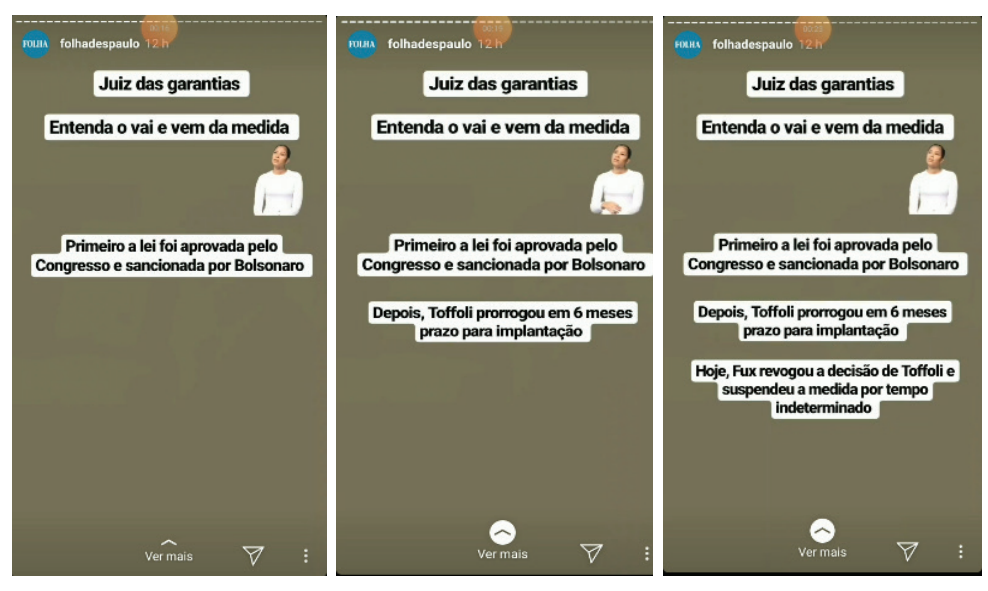

Fonte: Captura de tela. Elaborado pelas autoras. 
Somente em um episódio do \#nãodurmasemsaber a narrativa audiovisual foi explorada, com a apresentação, por um jornalista, de duas notícias. Este episódio contou ainda com texto de apoio e hiperlinks. Para demarcar a mudança de assunto, foi alterado o cenário da narrativa, como é possível verificar nas capturas de tela abaixo (Figura 5). Mais uma vez, a paleta de cores foi respeitada, garantindo um padrão estético visual entre texto e imagem.

\section{Figura 5 - episódio explora narrativa audiovisual}

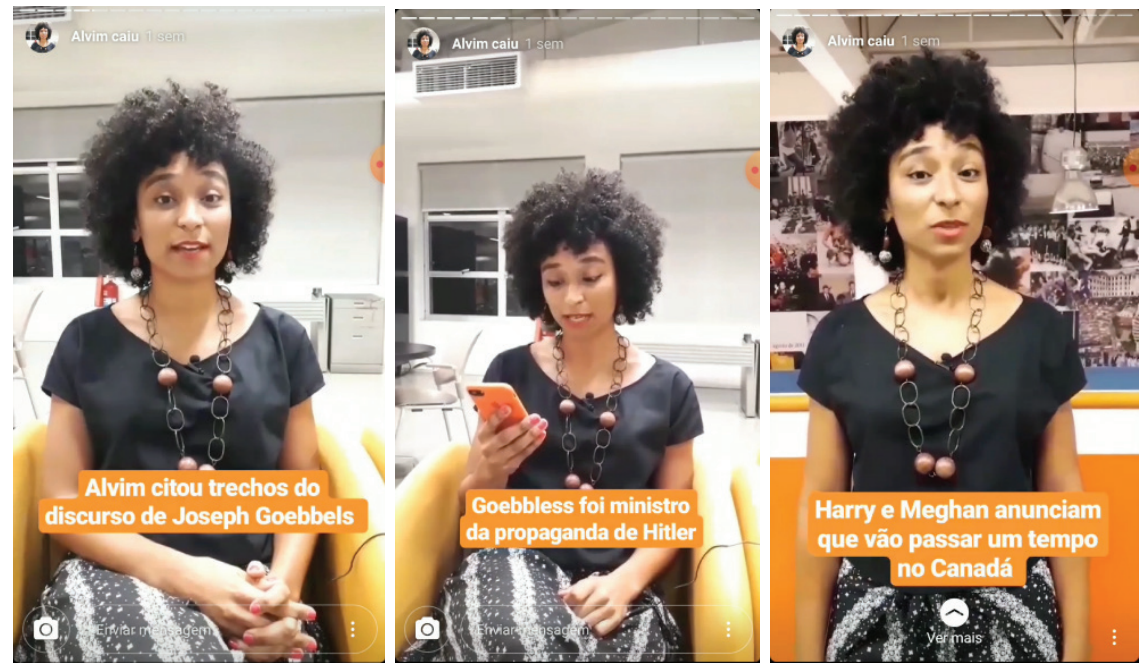

Fonte: Captura de tela. Elaborado pelas autoras.

Ainda que o conteúdo do \#nãodurmasemsaber seja majoritariamente nativo da plataforma, há pouca exploração dos recursos disponibilizados pelo Instagram. Além do texto, criado no próprio Story, a Folha utilizou como recursos adicionais hiperlinks, que aparecem em 100\% das publicações, além de GIFs, color cover, hashtag e o mention ${ }^{5}$.

Há uma batalha por atenção nesses espaços, e o conteúdo jornalístico luta para ser destaque na linha do tempo de stories dos usuários junto com outros, produzidos por amigos também usuários da plataforma. $\mathrm{Na}$ esteira da disputa pela atenção do usuário, há também o desafio de experimentar o mesmo formato utilizado pelos próprios, o que diz respeito à exploração das potencialidades ofertadas pela plataformas. No caso da Folha de S.Paulo e do \#nãodurmasemsaber, ainda que todo conteúdo pareça ser nativo, ainda é tímida a exploração dos recursos entregues, como menção de usuário, geolocalização, recursos de interação (call to action), GIF e hashtags, o que poderia expandir as possibilidades expressivas da narrativa e também a própria distribuição do conteúdo realizado dentro da própria plataforma. A utilização de recursos como as hashtags ${ }^{6}$, por exemplo, potencializa a dimensão hipertextual, comum desses espaços. Quando inserida uma hashtag, ela torna o texto da hashtag um hiperlink, ao clicar, o usuário é redirecionado para publicações que utilizaram a mesma hashtag, numa espécie de catálogo. Recentemente o Instagram adicionou a opção de busca por hashtag, o que tornou a ferramenta ainda mais importante, pois além de potencializar o conteúdo na rede, ela também se torna uma métrica importante para a verificar a dimensão e impacto do conteúdo.

O uso da geolocalização se insere nesse mesmo raciocínio. Quando um story menciona a localização, o usuário pode clicar sobre a tag de localização e verificar outras postagens já existentes na plataforma e que utilizaram a mesma tag. Por exemplo, ao produzir uma cobertura jornalística sobre um evento na Avenida Paulista, é possível, através da geolocalização do dispositivo, marcar o story com uma tag de localização. O usuário, quando olhar o story, poderá clicar sobre a tag e ver outras publicações que foram feitas no mesmo local. O men-

${ }^{5}$ Recursos disponibilizados pelo Instagram para a publicação de stories. A hashtag pode ser uma palavra ou uma frase que se escreve tudo junto (sem espaços) e que começa com o conhecido símbolo de "jogo-da-velha" (\#). No Instagram, as \# servem para organizar os conteúdos publicados. A “color cover", é a possibilidade de criar uma espécie de capa colorida e transparente para uma postagem. Um GIF (Graphics Interchange Format) é uma imagem em movimento.

${ }^{6}$ Uma hashtag é responsável pelo agrupamento de conteúdos na plataforma. 
tion (menção de usuário) talvez seja um dos recursos mais importantes, pois é a expressão da rede social. O recurso de mention consiste em um usuário marcar o perfil de outro usuário na rede. Ao clicar, o usuário pode visitar o perfil do usuário referido na publicação.

Segundo Recuero (2012), participar de interações online oportuniza aos indivíduos estabelecer relações e geração de laços sociais. No escopo da relação da geração de laços e aproximação com o leitor, o Instagram ainda disponibiliza diversos recursos de call to action, em que o usuário realiza ações no story (cliques, respostas), como enquete, perguntas e avaliação. Num ambiente competitivo, em que o que está em disputa é a atenção, a exploração de recursos próprios da plataforma pode ser uma escolha importante.

\section{Conclusão}

A influência das mídias sociais está moldando o ciberjornalismo (BELL \& OWEN, 2017). O crescente número de veículos de comunicação com perfis ativos no Instagram e publicando Stories, inclusive com criação de quadros especiais, é um dos indicadores desta tendência. É um lugar que as empresas jornalísticas têm ocupado para atingir um público cada vez maior e tentar sustentabilidade financeira para os conteúdos digitais. Além disso, os números expressivos do Instagram Stories ajudam a justificar a importância deste empreendimento e a provocar novas pesquisas na área.

Sinal dos tempos, a velocidade da informação é intensificada de forma crescente, o que, se por um lado tem suscitado preocupações no sentido do possível excesso de informação, por outro aparece como um motivo para novas estratégias de distribuição de conteúdo pelas organizações jornalísticas, que já vinham utilizando o Twitter e o Snapchat e, mais recentemente, rendem-se às potencialidades expressivas trazidas pelo Story.

Como foi possível observar no objeto empírico, o \#nãodurmasemsaber da Folha de S.Paulo, obedece, em certa medida, à nova lógica de consumo informacional, que, por sua vez, responde a uma dialética temporal do presente. Do ponto de vista do que foi avaliado, o conteúdo se insere na racionalidade contemporânea que reflete a efemeridade. Ainda que não explore todas as funcionalidades da plataforma, o conteúdo do quadro é rápido, objetivo e nativo da plataforma. Inserido num contexto de conexões efêmeras e fluídas, ele se incorpora no que fomos buscar em Fidalgo (2004), para compreender as dinâmicas relacionais trazidas pelas redes sociais para o jornalismo. A atualidade é uma corrida contra o tempo. "Pela actualidade o jornal, é do dia e para o dia. É como se fosse a luz de uma lanterna que foca apenas a actualidade". (FIDALGO, 2004, p. 8).

No entanto, a relação entre jornalismo e plataformas de rede sociais impõe alguns desafios. Ao jornalismo, é claro, e são diversos. No que tange à produção de notícias em microformatos, a partir do recorte analisado, percebe-se que a adaptação da produção noticiosa à plataforma carece de maior exploração dos recursos entregues pelo Instagram. Ainda que todo conteúdo pareça ser nativo, ou seja, produzido diretamente na plataforma, é tímida, pela Folha, a exploração de recursos como menção de usuário, geolocalização, hora e temperatura, GIF e hashtags, o que poderia expandir as possibilidades expressivas da narrativa, além de potencializar a distribuição da notícia, e criar uma conexão mais forte com o usuário.

Também é preciso ponderar que a plataforma é altamente versátil e serve o usuário e não a empresa jornalística. Dessa forma, conforme mudam os hábitos de consumo de seu público, ela também muda. Da mesma forma, a natureza efêmera dos stories se deve exclusivamente a uma condição específica da plataforma, definindo o desenvolvimento de mais uma prática para o jornalismo. Isso intensifica o desafio enfrentado pela mídia e também descortina um debate bastante hodierno 
quando se fala em jornalismo e plataformas de redes sociais; que sempre estará um passo atrás na escala de competitividade, pois o modelo de negócio jornalístico precisa se adaptar numa velocidade que transcende a convergência entre as plataformas de redes sociais e o jornalismo.

O fato é que as redes sociais estão em definitivo atravessando nosso tecido social. E se o consumo cada vez mais efêmero de conteúdo continuará sendo uma tendência, este seguirá sendo um vasto campo de investigação.

\section{ReferÊncia}

ALSINA, M. R. A construção da notícia. Petrópolis: Vozes, 2009.

ALVES, Y. M. Jornalismo em mídias sociais de imagens instantâneas: as narrativas jornalísticas em formato de stories no snapchat e instagram. 2018. Dissertação (Mestrado) - Programa de Pós-Graduação Mestrado Acadêmico em Comunicação e Sociedade, Universidade Federal do Tocantins, Palmas, 2018.

BARROS, L. S. Narrativas efêmeras do cotidiano: um estudo das Stories no Snapchat e no Instagram. 2017. Dissertação (Mestrado) - Programa de Pós-Graduação em Comunicação e Informação, Universidade Federal do Rio Grande do Sul, Porto Alegre, 2017.

BAUMAN, Z. Modernidade Líquida. São Paulo: Zahar, 2001.

CAMILLO, M. FERRARI, P. (Org.) Nós: tecnoconsequências sobre o humano (recurso eletrônico). Porto Alegre: Editora Fi, 2020. Disponível em: https://www. editorafi.org/771nos. Acesso em: 04 jun. 2020.

CASTELLS, M. A sociedade em rede. São Paulo: Paz e Terra, 2003.

ERBOLATO, M. L. Técnica de codificação em jornalismo: redação, captação e edição do jornal diário. Petrópolis: Vozes, 1979.

FIDALGO, A. Jornalismo Online segundo o modelo de Otto Groth. Biblioteca Online de Ciências da Comunicação/BOCC. Covilhã: Universidade de Beira Interior 2004. Disponível em: https://bit.ly/2CtoazW. Acesso em: 04 abr. 2020.

FLETCHER, R. e NIELSEN, R. K. Are people incidentally exposed to news on social media? A comparative analysis. New Media \& Society, v. 20, n. 7, p. 2450-2468, 2018.

GROTH, O. O Poder Cultural Desconhecido. Fundamentos da Ciência dos Jornais. Petrópolis: Vozes, 2011.

GRAINGE, P. (Ed.). Ephemeral Media. London: BFI, 2011, p. 138-155.

KANNENBERG, V;; SOUSA, M. E. O fantasmagórico site de rede social: como o Snapchat está sendo apropriado para a circulação de conteúdo jornalístico. In: Revista Brasileira de Ciências da Comunicação [s.l.], Intercom, São Paulo, v. 40, n. 3, p. 151-167, dez. 2017.

KANNENBERG, V. Senta que lá vem Stories: a apropriação do espaço efêmero do Ins- tagram pelo Jornalismo. In: CONGRESSO INTERNACIONAL DE CIBERJORNALISMO, 8., 2017, Campo Grande. Anais... Campo Grande: Ciberjor, 2017. Disponível em: http://www.ciberjor.ufms.br/ciberjor8/files/2017/08/artigo-vanessak-ciberjor.pdf. Acesso em: 20 abr. 2020. 
LEMOS, A. Cibercultura. Tecnologia e Vida Social na Cultura Contemporânea. Porto Alegre: Sulina, 2005.

NEWMAN, N. The rise of social media and its impact on mainstream journalism: A study of how newspapers and broadcasters in the UK and US are responding to a wave of participatory social media, and a historic shift in con- trol towards individual consumers [Report]. Reuters Institute for the Study of Journalism, 2009. Disponível em: https://bit.ly/2BwJmV1. Acesso em: 20 abr. 2020.

NEWMAN, N. Journalism, Media, And Technology Trends and Predictions 2016. Reuters Institute for the Study of Journalism, 2016. Disponível em: https:// bit.ly/2Nj3iO8. Acesso em: 04 abr. 2020.

NEWMAN, N. Journalism, Media, And Technology Trends and Predictions 2019. Reuters Institute for the Study of Journalism, 2019. Disponível em: https:// bit.ly/310BDJK. Acesso em: 04 abr. 2020.

RECUERO, R. Redes Sociais na Internet, Difusão de Informação e Jornalismo: Elementos para discussão, 2012. Disponível em: https://bit.ly/2BtGoAC. Acesso em: 16 jan. 2020.

SOCIAL MEDIA TRENDS FOR 2020 AND BEYOND. Influencers Marketing Hub, 2019. Disponível em: https://bit.ly/2YklPQ6. Acesso em: 20 abr. 2020.

GLOBAL SOCIAL MEDIA RANKING 2017. Statista, 2017. Disponível em: https://bit.ly/3hQhtIb. Acesso em: 20 abr. 2020.

VÁZQUEZ-HERRERO, J. DIREITO-REBOLLAL, S.; and LÓPEZ-GARCÍA, X. Ephemeral Journalism: News Distribution Through Instagram Stories. Social Media + Society. p. 1-13, Oct./Dec. 2019.

VASCONCELOS, E. L. Do impresso ao Snapchat: a efemeridade enquanto característica essencial do jornalismo. Revista Comunicação, Cultura e Sociedade, [S. 1.], v. 5, n. 1, p. 89-102, 2017. Disponível em: https://periodicos.unemat.br/index. php/ccs/article/view/2204. Acesso em: 15 jan. 2020.

BITTERLY, M.; FEE, M.; MITCHELL, T. Looking Forward to 2020, Here are 10 Themes for News. New York Times. Disponível em: https://nyti.ms/2YpMM5j. Acesso em: 04 abr. 2020. 